\title{
The gene expression of adenosine receptors in the processes of contrast induced nephropathy in mouse kidney
}

\author{
Luyu Yao ${ }^{1}$, Cynthia Zhao ${ }^{2}$, Xin Gu², Gopi K. Kolluru², Christopher G. Kevil ${ }^{2}$, Wayne W. Zhang ${ }^{{ }^{*}}$ \\ ${ }^{1}$ Department of Surgery, Louisiana State University Health Sciences Center, Shreveport, USA \\ ${ }^{2}$ Department of Pathology, Louisiana State University Health Sciences Center, Shreveport, USA \\ Email: ${ }^{*}$ wzhan2@1suhsc.edu
}

Received 24 September 2013; revised 26 October 2013; accepted 15 November 2013

Copyright (C) 2013 Luyu Yao et al. This is an open access article distributed under the Creative Commons Attribution License, which permits unrestricted use, distribution, and reproduction in any medium, provided the original work is properly cited.

\begin{abstract}
Objective: Contrast induced nephropathy (CIN) is the third leading cause of hospital acquired renal failure. The mechanism of CIN is not fully understood. The objectives of this study were to investigate the expression changes of the four subtypes of adenosine receptors $\left(A_{1} A R, A_{2 A} A R, A_{2 B} A R\right.$, and $\left.A_{3} A R\right)$ following administration of contrast media in mice. Methods: C57BL/6J mice were randomized into treatment and control groups. Iodixanol (IDX) was administered to two treatment groups through retroorbital injection at two different dosages, $0.75 \mathrm{gI} / \mathrm{kg}$ and $2.75 \mathrm{gI} / \mathrm{kg}$. Phosphate buffered saline (PBS) was given to the control group. Mice kidneys were harvested at day 3 and day 7 after Iodixanol administration. Kidney injuries and function were evaluated according to Hematoxylin and eosin stain, Ki67 protein expression, and TUNEL assay of paraffin embedded kidney sections, and plasma creatinine assay. RNA and protein were extracted from the kidney specimens. $A_{1} A R, A_{2 A} A R, A_{2 B} A R$, and $A_{3} A R$ RNA and protein level of the samples were assessed using qRT-PCR and Western blotting, with GAPDH as an endogenous control. Results: H\&E staining showed no significant histopathology injuries after Iodixanol administration. No evidence of kidney injury and functional impairment was found. However, there was an increased number of $A_{1} A R, A_{2 A} A R, A_{2 B} A R$, and $A_{3} A R$ RNA transcripts detected in the kidney 3 days after Iodixanol injection. The RNA levels in all the four subtypes of adenosine receptors were increased 2 - 3 fold in the day 3 specimens and back to normal at day 7. Western blot demonstrated that $A_{1} A R, A_{2 A} A R$, and $A_{3} A R$ expression increased 1.5 to 2 fold at day 3 and day 7 following Iodixanol injection. $\mathrm{A}_{2 \mathrm{~B}} \mathrm{AR}$ baseline expression was low in normal phy-

${ }^{*}$ Corresponding author.
\end{abstract}

siological conditions and no significant change was detected by Western blot. Conclusions: Iodixanol significantly increases adenosine receptors gene expression in mice. This suggests that adenosine receptors may play a role in the development of CIN.

Keywords: Contrast Induced Nephropathy; Adenosine Receptor; Iodixanol

\section{INTRODUCTION}

In clinical radiologic examinations, including coronary angiography, peripheral angiography and computed tomography angiography (CTA) contrast media have to be used. It is also required for mini-invasive interventional and endovascular procedures. However, contrast media may cause acute kidney dysfunction, especially in patients with preexisting underlying diseases, such as hypertension, diabetes mellitus, or renal insufficiency. This acute renal function deterioration following intravascular contrast imaging study is called contrast induced nephropathy (CIN).

CIN continues to be the third leading cause of hospital acquired renal failure (ARF) for over three decades. It not only excludes numbers of patients from important imaging studies, such as CTA and digital subtraction angiogram, but also deprives the patients of less invasive endovascular procedures. Although it was suggested that contrast media may cause reduced vasodilatation and increased vasoconstriction resulting in kidney local ischemia and hypoxia [1-3], the mechanisms of CIN have not been fully understood.

Adenosine, a metabolite of ATP hydrolysis, is a potent renal vasoconstrictor which plays a role in signal transmission of tubuloglomerular feedback [4]. In the kidney, during states of increased energy metabolism that occurs during increased tubular transport, i.e., contrast media administration, ATP is hydrolyzed to adenosine diphos- 
phate and 5'-AMP. Then 5'-AMP is hydrolyzed by 5'nucleotidase to adenosine $[2,4]$. There are reports suggesting that adenosine receptor antagonists may prevent CIN [5-7]. Thus adenosine release and adenosine receptor stimulation may play a role in CIN development [2].

There are reports indicating that the adenosine receptors' expression is changed during ischemic, hypoxic, and inflammation conditions [8-13]. We were curious whether contrast media might alter the adenosine receptors' expression. The objectives of this study were to investigate the expressions of the four subtypes of adenosine receptors $\left(A_{1} A R, A_{2 A} A R, A_{2 B} A R\right.$, and $\left.A_{3} A R\right)$ following administration of contrast media in mice.

\section{MATERIALS AND METHODS}

\subsection{Animals}

Normal C57BL/6J mice, JAX stock number 000664, were utilized. Seven-week-old male mice were obtained and accommodated in the central animal facility at Louisiana State University Health Sciences Center Shreveport for one week before experiments. All animals were from The Jackson Laboratory. They were caged with free access to food and water under conditions of $21^{\circ} \mathrm{C} \pm 1{ }^{\circ} \mathrm{C}$ and $50 \%$ to $80 \%$ relative humidity at all times in an alternative 12-hour light-dark cycle. All animal maintenance and treatment protocols were in compliance with the Guide for Care and Use of Laboratory Animals as adopted and promulgated by the National Institutes of Health, and were approved by the Animal Care and Use Committee at the Louisiana State University Health Sciences Center Shreveport.

\subsection{Iodixanol Administration}

Eight-week-old C57BL/6J mice were anesthetized with $150 \mathrm{mg} / \mathrm{kg}$ Ketamine and $10 \mathrm{mg} / \mathrm{kg}$ Xylazine. Then Iodixanol (IDX) was retro-orbitally injected into the mice at doses of $0.75 \mathrm{gI} / \mathrm{kg}(\mathrm{n}=3)$ and $2.75 \mathrm{gI} / \mathrm{kg}(\mathrm{n}=3)$. A $0.9 \%$ saline solution instead of Iodixanol was injected into the mice in the control group $(\mathrm{n}=3)$. Three days and 7 days after Iodixanol administration, the animals were sacrificed. Their kidneys were harvested, cut sagittally, and placed into labeled cassettes with $10 \%$ neutral formalin fixation for 24 hours at room temperature. The kidney sections were then embedded into paraffin. The other parts of the kidneys used for protein extraction were snap frozen in liquid nitrogen and stored in an $-80^{\circ} \mathrm{C}$ refrigerator. The kidney parts used for RNA extraction were put into 10 volumes of RNAlater (Ambion) at $4^{\circ} \mathrm{C}$ overnight and then stored in an $-80^{\circ} \mathrm{C}$ refrigerator.

\subsection{Histopathology and Histology Scoring}

Histopathology evaluation was performed as described by Hoffmann et al. [14]. Briefly, the embedded tissues were cut into 5- $\mu \mathrm{m}$ sections and stained with Hematoxylin and eosin stain (H\&E stain). The histology damage of the sections was evaluated under a light microscope by a pathologist, who was blind to this study. A severity score based on grading scales of 0 - 3 was used to grade pathological damages of the kidney: 0 , none to minimal damage; 1 , mild acute tubular injury manifested by mild tubular distension, a low epithelial lining, and nonspecific degenerative changes of the epithelial cells; 2 , moderate acute tubular injury, with frequent single cell necrosis within the epithelial layer; and 3, severe acute tubular injury demonstrated by the presence of widespread epithelial cell necrosis, low epithelial lining, and accumulation of cellular debris in the tubule lumens.

\subsection{Immunohistochemical (IHC) Procedures}

Paraffin-embedded specimens were cut into $5-\mu \mathrm{m}$ sections. The slides were deparaffinized and dehydrated. For antigen retrieval purposes, slides were put into a vessel containing sodium citrate buffer $(10 \mathrm{mM}$ sodium citrate, $0.05 \%$ Tween $20, \mathrm{pH} 6.0$ ) and were heated approaching $100^{\circ} \mathrm{C}$ for about 20 minutes. Endogenous peroxidase was inhibited with $0.3 \%$ peroxide in $50 \%$ methanol (in PBS) for 30 minutes at room temperature. The slides were washed with PBS three times, and then blocked for 20 minutes with $2.5 \%$ normal goat serum. Next, the primary antibody, rabbit anti mouse Ki67 antibody (Abcam, Cambridge, MA), was diluted 100 times in $0.1 \%$ normal goat serum PBS solution and put onto the slides and incubated for 1 hour at room temperature. Slides were washed with PBS five times, and then the secondary antibody, goat anti rabbit IgG-HRP (Abcam, Cambridge, MA) diluted 500 times in $0.1 \%$ normal goat serum PBS solution, was added onto the slides and incubated for 1 hour at room temperature. The slides were again washed with PBS three times. Following this, Chromogen 3,3'Diaminobenzidine (DAB) (Abcam, Cambridge, MA) was added onto the slides prior to incubating for another 7 minutes. After a PBS rinse, the slides were counter stained with hematoxylin (Sigma-Aldrich, St. Louis, MO) for 2 minutes and rinsed under tap water for 5 minutes. Slides were then dehydrated. Finally, cover slips were mounted onto the slides with permount.

\subsection{Terminal Deoxynucleotidyl Transferase Mediated dUTP Nick end Labeling (TUNEL) Assay Procedures}

Paraffin-embedded specimens were cut into $5-\mu \mathrm{m}$ sections. The slides were deparaffinized and dehydrated. Apoptosis of samples were identified using an In Situ Cell Death Detection Kit POD (Roche Applied Science, Mannheim, Germany), based on labeling of DNA strand 
bricks (TUNEL technology). Briefly, endogenous peroxidase was inhibited with $0.3 \%$ peroxide in $50 \%$ methanol (in PBS) for 30 minutes at room temperature after dehydration. The slides were washed with PBS three times, and then permeabilized by $20 \mu \mathrm{g} / \mathrm{ml}$ Proteinase $\mathrm{K}$ (in $10 \mathrm{mM}$ Tris/ $\mathrm{HCl}, \mathrm{pH} 7.4$ - 8.0) for 30 minutes at room temperature. Slides were washed with PBS three times, then samples were incubated with the TUNEL reaction mixture, containing fluorescein (FITC) labeled dUTP and terminal deoxynucleotidyl transferase, in a humidified chamber for 1 hour at $37^{\circ} \mathrm{C}$. Control slides were incubated in the absence (negative control) of terminal deoxynucleotidyl transferase, or presence (positive control) of DNase I. After PBS washes three times, slides were blocked by $2.5 \%$ sheep serum in PBS for 20 minutes in room temperature. Slides were washed with PBS three times, and then converter-POD (Anti-fluorescin antibody conjugated with horseradish peroxidase from sheep) was added onto each slide and slides were incubated in a humidified chamber for 30 minutes at $37^{\circ} \mathrm{C}$. The slides were again washed with PBS three times. Following this, Chromogen 3,3'-Diaminobenzidine (DAB) (Abcam, Cambridge, MA) was added onto the slides prior to incubating for another 10 minutes at room temperature. After a PBS rinse, the slides were counter stained with hematoxylin (Sigma-Aldrich, St. Louis, MO) for 2 minutes and rinsed under tap water for 5 minutes. Slides were then dehydrated. Finally, cover slips were mounted onto the slides with permount.

\subsection{Serum Creatinine Level Analysis}

Mouse serum was collected at day 3 and day 7 time point. Plasma creatinine level was measured by creatinine assay kit (BioVision, Milpitas, CA) following the product instructions. Results are represented as means \pm standard deviation (SD).

\subsection{Quantitative Real-Time PCR}

Kidney samples were taken out from the RNAlater, and a slice from each sample was cut off and weighed. The total RNA of the specimen was isolated using an RNeasy mini kit (QIAGEN, Valencia, CA). First-strand cDNAs were synthesized from total RNA by reverse transcription ( $1 \mu \mathrm{g}$ total RNA in $20 \mu \mathrm{l}$ of reaction volume) using the iScript cDNA Synthesis Kit (Bio-Rad Laboratories, Hercules, CA) primed with oligo dT and random hexamer primers. SsoFast EvaGreen Supermix (Bio-Rad Laboratories, Hercules, CA) was used for dye-based detection. Reactions were conducted in a CFX96 Touch $^{\mathrm{TM}}$ Real-Time PCR Detection System (Bio-Rad Laboratories, Hercules, CA). Fluorescence was monitored during every PCR cycle at the annealing step. The primers for adenosine receptors were: $A_{1}, 5$ '-AGC CTA CTA TTA
GGT GTT-3', 5'-GCA TAT CCA TTT CTC TCT AT-3';

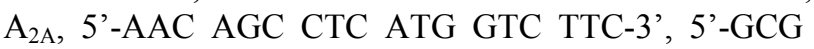
TTT CTT CTC TTC TCT TAA-3'; A $_{2 B}, 5^{\prime}$-ATG TCT CTT TGA GAA TGT-3', 5'-TAG ATC ACC AGC ATT ATG-3'; A $_{3}$, 5'-CAG TCT GTG TCT ATG ATG-3', 5'-GGT GAA GGC AAT AAT GTT-3'; GADPH: 5'-GAG TCA ACG GAT TTG GTC GT-3', 5'-TTG ATT TTG GAG GGA TCT CG-3'. PCR conditions were as follows: $95^{\circ} \mathrm{C}, 30 \mathrm{~s} ;\left(95^{\circ} \mathrm{C}, 2 \mathrm{~s} ; 55^{\circ} \mathrm{C}, 2 \mathrm{~s}\right) \times 40$ cycles; $60^{\circ} \mathrm{C}, 1 \mathrm{~min}$; Melt curve: $65^{\circ} \mathrm{C}-95^{\circ} \mathrm{C}$ in $0.5^{\circ} \mathrm{C}$ interval, 2 s/step. Results were analyzed with a Bio-Rad CFX manager. Results for all experiments represent triplicate determinations. Results are represented as means \pm SD.

\subsection{Western Blot Analysis}

Kidney samples were homogenized in RIPA buffer (150 $\mathrm{mM} \mathrm{NaCl}, 1 \%$ Triton $\times 100,0.5 \%$ Sodium deoxycholate, $0.1 \%$ SDS, $50 \mathrm{mM}$ Tris-Cl $\mathrm{pH} 8.0$ supplemented with 2 $\mu \mathrm{g} / \mathrm{ml}$ of aprotinin, $2 \mu \mathrm{g} / \mathrm{ml}$ of leupeptin, $40 \mu \mathrm{g} / \mathrm{ml}$ of phenylmethylsulfonyl fluoride). Protein of the samples were extracted. Approximately $10-20 \mu \mathrm{g}$ of total proteins were separated on a $10 \%$ SDS-polyacrylamide gel and transferred to a polyvinylidene difluoride membrane (Bio-Rad Laboratories, Hercules, CA). The membrane was incubated for 1 hour at room temperature in a block buffer (TBS containing $0.03 \%$ Tween $20 \%$ and $5 \%$ fatfree milk power). The blots were probed with antibodies specific for $\mathrm{A}_{1}$ (Abcam, Cambridge, MA), $\mathrm{A}_{2 \mathrm{~A}}$ (Biorbyt Limited, Cambridge, United Kingdom), $\mathrm{A}_{2 \mathrm{~B}}$ (Santa Cruz Biotechnology, Santa Cruz, CA), A 3 (Biorbyt Limited, Cambridge, United Kingdom) receptors or GAPDH (Santa Cruz Biotechnology, Santa Cruz, CA) at $4^{\circ} \mathrm{C}$ overnight respectively. Membranes were washed three times at 10 minutes per washing with $0.03 \%$ Tween 20 in TBS, and were then incubated with the secondary antibody for 1 hour at room temperature. Membranes were washed again three times and developed using ECL Western Blotting Substrate (Thermo Scientific, Waltham, MA).

\subsection{Statistical Methods}

Statistical analysis of changes in adenosine receptors RNA and protein expression were performed with Student's $t$-test using Prism software (GraphPad Software, Inc., La Jolla, CA). A $P$ value of 0.05 or less was considered statistically significant. Data are expressed as means \pm SD.

\section{RESULTS}

\subsection{Histopathology Injuries of Kidney after Iodixanol Administration in Normal C57BL/6J Mice}

H\&E staining showed no significant histopathological 
damages after Iodixanol administration in normal C57BL/6J mice. Our results of H\&E staining (Figure 1) and histology scoring demonstrated that all the PBS treated and Iodixanol treated mice had no to minimal injury, with a score of 0 . There was no significant difference between control groups and the treatment groups of the mice treated with Iodixanol, i.e., there was no significant histological evidence of CIN in Iodixnaol treated mice.

\subsection{Ki67 Expression after Iodixanol Administration in Normal C57BL/6J Mice}

The IHC results (Figure 2) revealed that Iodixanol did not add any further damage to the kidneys of the normal $\mathrm{C} 57 \mathrm{BL} / 6 \mathrm{~J}$ mice, as there was no increase of Ki67 expression after Iodixanol administration. There was no evidence of renal cell proliferation which indicates renal injury in Iodixnaol treated mice.

\subsection{TUNEL Assay Results after Iodixanol Administration in Normal C57BL/6J Mice}

Our TUNEL data does not show any significant apoptosis in Iodixanol treated samples (Figure 3). There was no evidence of renal cell apoptosis in Iodixnaol treated mice.

\subsection{Creatinine Assay Results after Iodixanol Administration in Normal C57BL/6J Mice}

The mouse plasma creatinine data does not show any significant increase in Iodixanol treated samples (Table 1). CIN was not induced in normal mice after Iodixanol administration.

\subsection{Adenosine Receptors Expression Changes after Iodixanol Administration in Normal C57BL/6J Mice}

The qRT-PCR results (Figure 4) showed that Iodixanol induced transcription of all the four adenosine receptor subtypes, which was more obvious in the group treated with the dosage of $2.75 \mathrm{gI} / \mathrm{kg}$ day 3 after injection. The RNA levels in all the four subtypes of adenosine receptors were increased 2 - 3 fold at day 3 , but were back to normal at day 7. The Western blot results (Figure 5) showed that $\mathrm{A}_{1} \mathrm{AR}, \mathrm{A}_{2 \mathrm{~A}} \mathrm{AR}, \mathrm{A}_{3} \mathrm{AR}$ expression increased 1.5 to 2 fold at day 3 and day 7 following Iodixanol injection. The baseline $A_{2 B} A R$ expression was very low and no significant change was detected by Western blot.

\section{DISCUSSION}

Adenosine is a tissue hormone that is locally generated in many organs. It binds to the cell surface of adenosine receptors to mediate a vast array of physiological functions, including cardiac rate and contractility, smooth muscle tone, neurotransmitter release, sedation, lipolysis, white blood cell function, platelet function, and renal function [15]. There are four different adenosine receptors (AR) named $\mathrm{A}_{1}, \mathrm{~A}_{2 \mathrm{~A}}, \mathrm{~A}_{2 \mathrm{~B}}$, and $\mathrm{A}_{3}$. They are $\mathrm{G}$ protein coupled receptors. The $A_{2 A}$ and $A_{2 B}$ preferentially interact with members of Gs family of proteins and the $\mathrm{A}_{1}$ and $\mathrm{A}_{3}$ interact with Gi/o proteins [16].

Adenosine release and adenosine receptor stimulation were proposed to be pathophysiologic factors in the de-
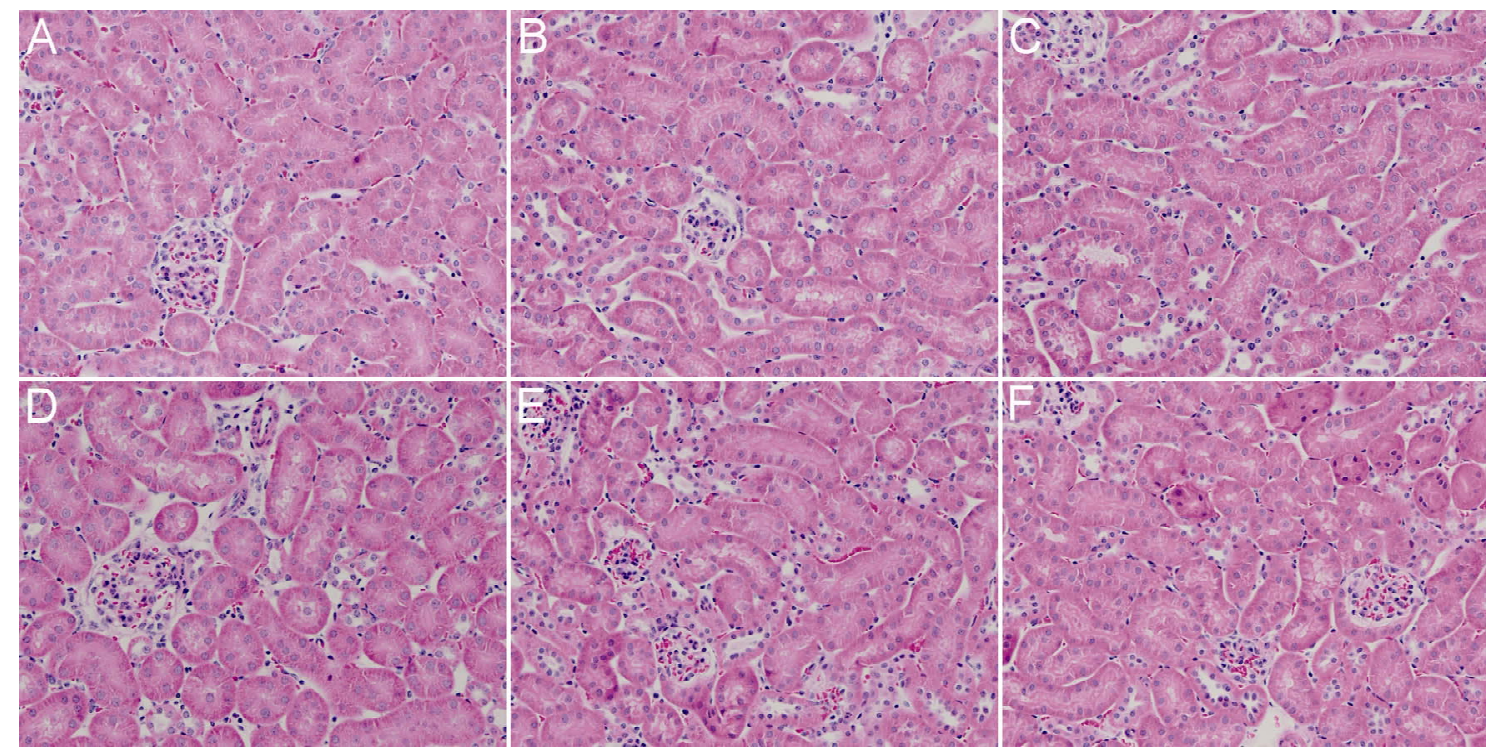

Figure 1. Representative images of H\&E-stained kidney histology sections of PBS treated versus Iodixanol treated mice. A, PBS control, day 3. B, $0.75 \mathrm{gI} / \mathrm{kg}$ Iodixnaol, day 3. C, $2.75 \mathrm{gI} / \mathrm{kg}$ Iodixnaol, day 3. D, PBS control, day 7. E, $0.75 \mathrm{gI} / \mathrm{kg}$ Iodixnaol, day 7. F, $2.75 \mathrm{gI} / \mathrm{kg}$ Iodixnaol, day 7. No evidence of kidney injuries was found $(\times 200)$. 


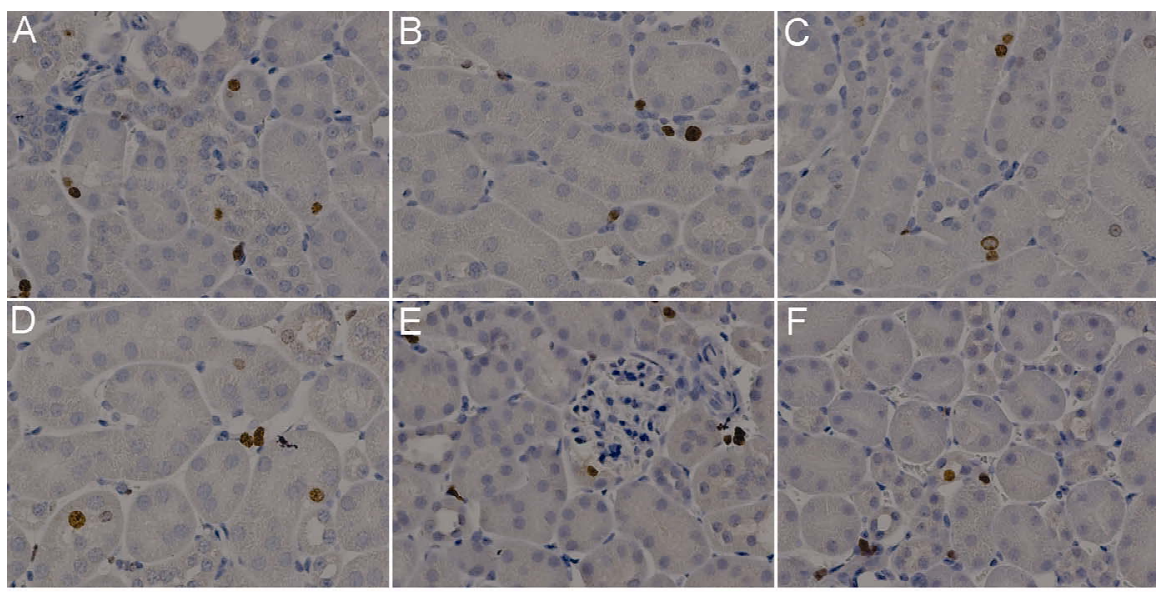

G

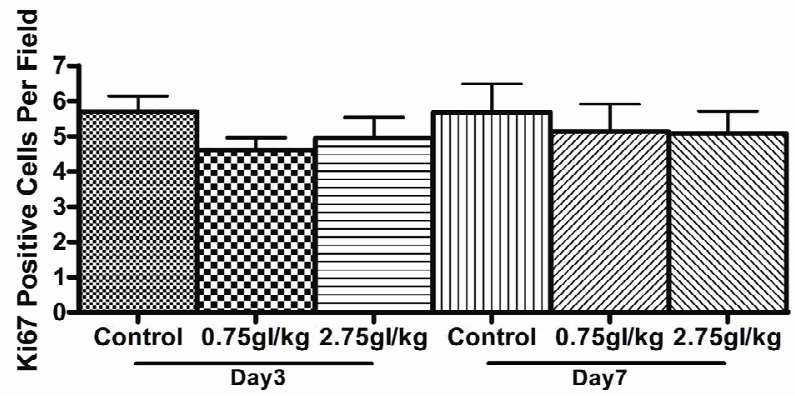

Figure 2. Representative images of Ki67 IHC results of kidney histology sections in PBS treated versus Iodixanol treated mice. A, PBS control, day 3. B, $0.75 \mathrm{gI} / \mathrm{kg}$ Iodixnaol, day 3 . C, $2.75 \mathrm{gI} / \mathrm{kg}$ Iodixnaol, day 3. D, PBS control, day 7 . E, $0.75 \mathrm{gI} / \mathrm{kg}$ Iodixnaol, day $7 . \mathrm{F}$, $2.75 \mathrm{gI} / \mathrm{kg}$ Iodixnaol, day 7. G, Ki67 expression level calculated according to Ki67 IHC results. No significant differences between PBS and Iodixanol treated groups $(\times 200)$.
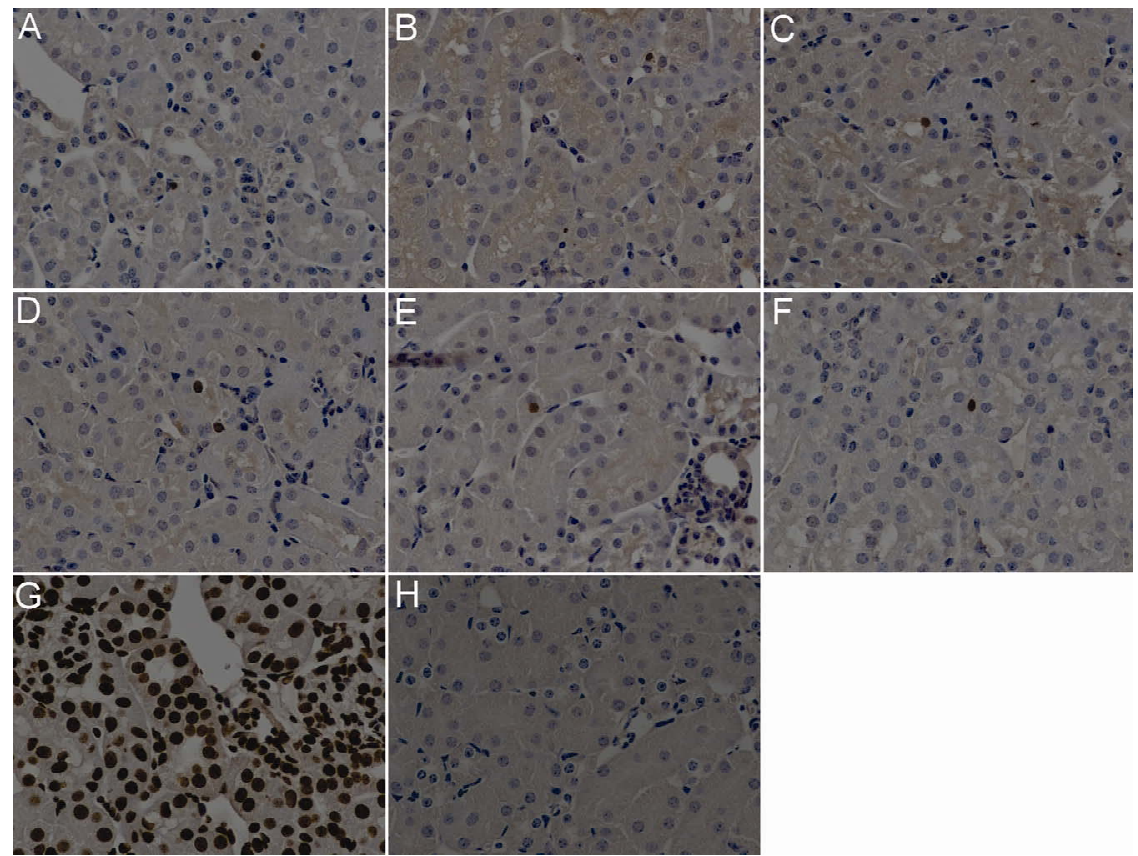

Figure 3. Representative images of TUNEL results of kidney histology sections in PBS treated versus Iodixanol treated mice. A, PBS control, day $3 . \mathrm{B}, 0.75 \mathrm{gI} / \mathrm{kg}$ Iodixnaol, day 3. C, $2.75 \mathrm{gI} / \mathrm{kg}$ Iodixnaol, day 3. D, PBS control, day 7. E, $0.75 \mathrm{gI} / \mathrm{kg}$ Iodixnaol, day 7. F, $2.75 \mathrm{gI} / \mathrm{kg}$ Iodixnaol, day 7. G, positivie control. H, negative control. No significant differences between PBS and Iodixanol treated groups $(\times 200)$. 
A

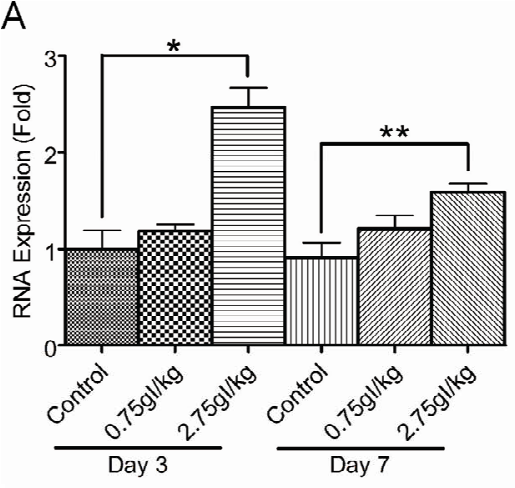

C

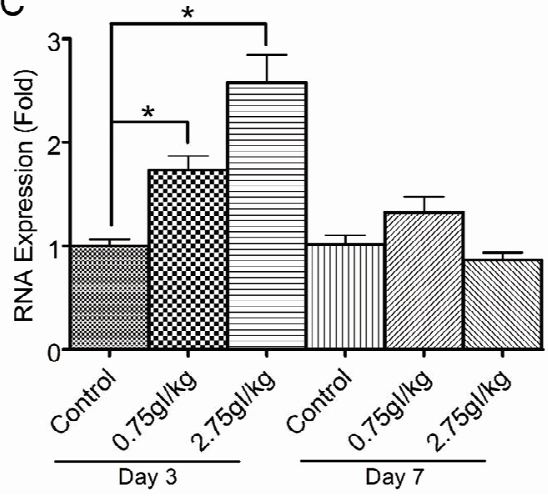

$\mathrm{B}$

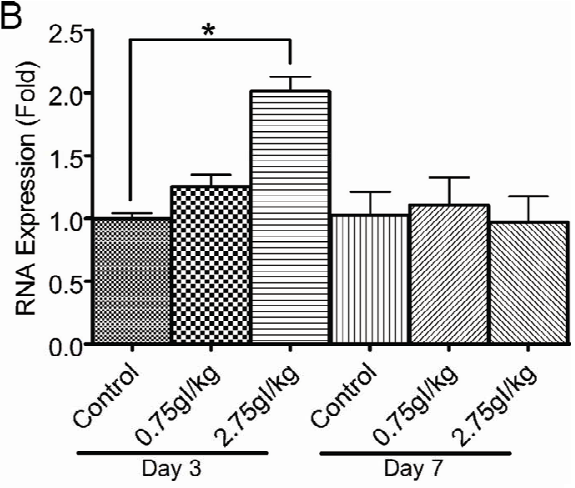

D

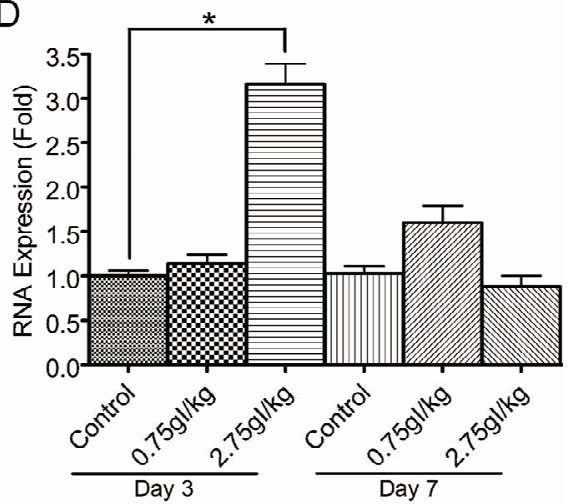

Figure 4. mRNA levels of $A, A_{1} A R, B, A_{2 A} A R, C, A_{2 B} A R, D, A_{3} A R$, in PBS treated versus Iodixanol treated mice kidney. ${ }^{*} \mathrm{P}<0.01(\mathrm{n}=3),{ }^{* * *} \mathrm{P}<0.05(\mathrm{n}=3)$.

A

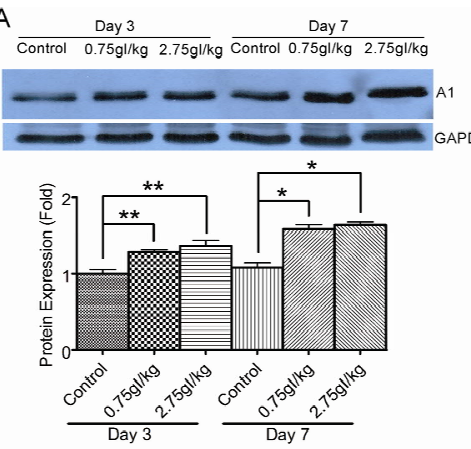

$\mathrm{B}$
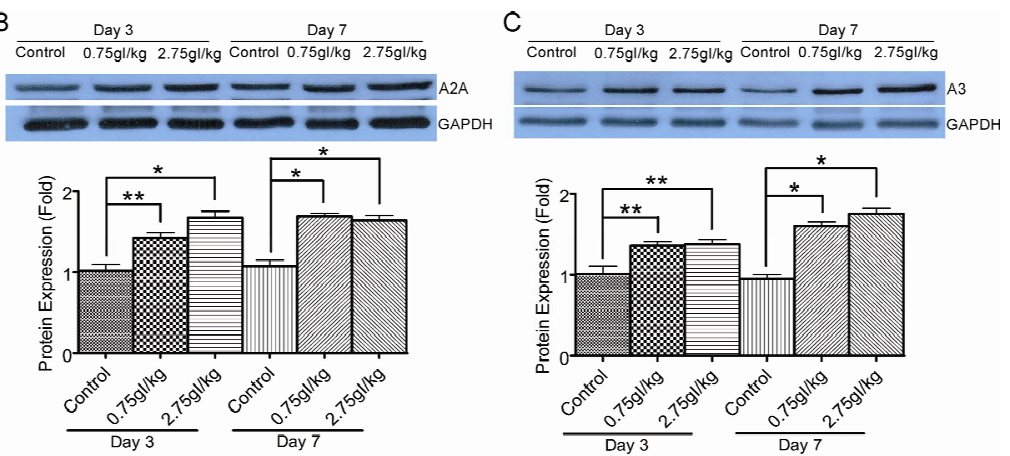

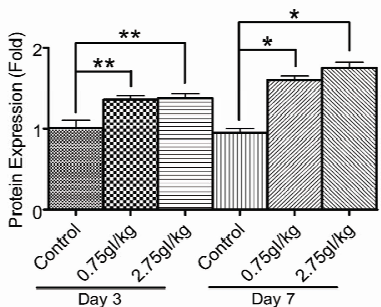

Figure 5. Representative Western blot results of $A, A_{1} A R, B, A_{2 A} A R, C, A_{3} A R$, in PBS treated versus Iodixanol treated mice kidney. ${ }^{*} \mathrm{P}<0.01(\mathrm{n}=3),{ }^{* * *} \mathrm{P}<0.05(\mathrm{n}=3)$.

Table 1. Mouse plasma creatinine level (each group $n=3$ ).

\begin{tabular}{ccccccc}
\hline Group & Control Day 3 & $\begin{array}{c}\text { IDX 0.75 gI } / \mathrm{kg} \\
\text { Day 3 }\end{array}$ & $\begin{array}{c}\text { IDX 2.75 gI } / \mathrm{kg} \\
\text { Day 3 }\end{array}$ & Control Day 7 & $\begin{array}{c}\text { IDX 0.75 gI } / \mathrm{kg} \\
\text { Day 7 }\end{array}$ & $\begin{array}{c}\text { IDX 2.75 gI } / \mathrm{kg} \\
\text { Day 7 }\end{array}$ \\
\hline Creatinine $( \pm \mathrm{SD})(\mathrm{mg} / \mathrm{dL})$ & $0.578 \pm 0.080$ & $0.509 \pm 0.156$ & $0.652 \pm 0.087$ & $0.633 \pm 0.068$ & $0.586 \pm 0.182$ & $0.527 \pm 0.062$ \\
\hline
\end{tabular}

velopment of CIN. In the kidney, adenosine modulates vascular and tubular function primarily via $\mathrm{A}_{1}$ and $\mathrm{A}_{2 \mathrm{~A}}$ adenosine receptors, which are distributed throughout the kidney with a predominance of $A_{1}$ receptors presenting on the afferent arteriole and renal tubules. $A_{2 \mathrm{~A}}$ receptors are primarily located on the efferent arteriole. This distribution pattern decides the responses of renal blood vessels to adenosine. Although stimulation of $\mathrm{A}_{2 \mathrm{~A}}$ receptors, which are coupled to Gs protein, causes vasodilation, the adenosine itself induces vasoconstrictions of the afferent glomerular arteriole via $\mathrm{A}_{1}$ receptors and overall decreases renal blood flow [2]. In this study, we investigated the expression changes of the four subtypes of adenosine receptors $\left(\mathrm{A}_{1} \mathrm{AR}, \mathrm{A}_{2 \mathrm{~A}} \mathrm{AR}, \mathrm{A}_{2 \mathrm{~B}} \mathrm{AR}\right.$, and $\left.\mathrm{A}_{3} \mathrm{AR}\right)$ 
following administration of contrast media in normal mice. Our histological, Ki67, TUNEL and creatinine assay results showed no evidence of CIN caused by Iodixanol, but Iodixanol did increase the expression of the four adenosine receptor subtypes in these young, normal mice.

It has been documented that patients with preexisting renal diseases are vulnerable to CIN [17-20], but healthy people are not $[21,22]$. Similarly, it is understandable that CIN with obvious renal cell apoptosis and proliferation may be difficult to be induced in normal healthy mice. The useful CIN animal model is not available at present [23]. Although these mice treated with Iodixanol did not develop CIN, the observation of the responses of normal kidney to contrast media can still provide us with useful information for further study in CIN mechanisms.

Previous studies suggest that contrast media can cause the increase of adenosine levels [2,4,24], and adenosine accumulation reduces renal blood flow via $A_{1}$ receptor stimulation, which is believed to be one of the mechanisms of CIN [2]. Our results demonstrated that the adenosine receptors' expression was significantly up-regulated by contrast media in a healthy mouse, which means that the renal cells will be more sensitive to adenosine signal, because the higher the number of receptors, the more potent or efficacious the agonist will be. The rather low levels of endogenous adenosine presenting under basal physiological conditions have the potential of activating receptors where they are abundant, but not where they are sparse [16]. This may exacerbate the effect of adenosine release and makes the kidney more vulnerable to CIN [2].

As we mentioned earlier, healthy people's kidneys are resistant to CIN [21,22]. Although our data showed that Iodixanol failed induce $\mathrm{CIN}$, it did increase the expression of adenosine receptors. The possible explanations are: 1) Iodixanol, as a new generation of iso-osmolar contrast agent, may be less toxic to the kidney; 2) CIN may only present with transient renal dysfunction without significant histological damages to the normal kidneys in healthy mice. Since adenosine receptor expression is changed during ischemic, hypoxic, and inflammation conditions [8-13], the pre-existing kidney diseases may be also required in the development of CIN. Further investigation using $\mathrm{db} / \mathrm{db}$ and hypertension mice will be carried out in our research lab.

Our data also demonstrated that the adenosine receptor transcription was elevated at day 3 following Iodixanol administration, and recovered to normal at day 7 . This trend is consistent with the renal function changes in clinical patients, in whom serum creatinine usually reaches the peak level within 3 - 5 days and start recovering after 5 - 7 days following contrast imaging studies.

\section{CONCLUSION}

Iodixanol, an intravenous contrast media, significantly increases adenosine receptor gene expression in normal mice. Since the adenosine release and adenosine receptor stimulation were proposed to be pathophysiologic factors in the development of CIN [2], although the CIN was not induced in the normal mice, we presume that the adenosine receptor expression increase we found in normal mice may play a role in the CIN development by exacerbating adenosine-induced vasoconstriction. Further study should focus on whether this alteration really plays a role in CIN development using animal models that actually developed CIN. We plan to use $\mathrm{db} / \mathrm{db}$ and hypertension mice treated with Iodixanol or other contrast media to do this further study.

\section{REFERENCES}

[1] Gleeson, T.G. and Bulugahapitiya, S. (2004) Contrast-induced nephropathy. American Journal of Roentgenology, 183, 1673-1689.

http://dx.doi.org/10.2214/ajr.183.6.01831673

[2] Pflueger, A., Larson, T.S., Nath, K.A., King, B.F., Gross, J.M. and Knox, F.G. (2000) Role of adenosine in contrast media-induced acute renal failure in diabetes mellitus. Mayo Clinic Proceedings, 75, 1275-1283.

[3] Sendeski, M., Patzak, A., Pallone, T.L., Cao, C., Persson, A.E. and Persson, P.B. (2009) Iodixanol, constriction of medullary descending vasa recta, and risk for contrast medium-induced nephropathy. Radiology, 251, 697-704. http://dx.doi.org/10.1148/radiol.2513081732

[4] Osswald, H., Hermes, H.H. and Nabakowski, G. (1982) Role of adenosine in signal transmission of tubuloglomerular feedback. Kidney International Supplements, 12, S136-S142.

[5] Erley, C.M., Duda, S.H., Schlepckow, S., et al. (1994) Adenosine antagonist theophylline prevents the reduction of glomerular filtration rate after contrast media application. Kidney International, 45, 1425-1431.

http://dx.doi.org/10.1038/ki.1994.186

[6] Kolonko, A., Wiecek, A. and Kokot, F. (1998) The nonselective adenosine antagonist theophylline does prevent renal dysfunction induced by radiographic contrast agents. Journal of Nephrology, 11, 151-156.

[7] Katholi, R.E., Taylor, G.J., McCann, W.P., et al. (1995) Nephrotoxicity from contrast media: Attenuation with theophylline. Radiology, 195, 17-22.

[8] Yap, S.C. and Lee, H.T. (2012) Adenosine and protection from acute kidney injury. Current Opinion in Nephrology and Hypertension, 21, 24-32. http://dx.doi.org/10.1097/MNH.0b013e32834d2ec9

[9] Bauerle, J.D., Grenz, A., Kim, J.H., Lee, H.T. and Eltzschig, H.K. (2011) Adenosine generation and signaling during acute kidney injury. Journal of the American Society of Nephrology, 22, 14-20. http://dx.doi.org/10.1681/ASN.2009121217 
[10] Eckle, T., Grenz, A., Laucher, S. and Eltzschig, H.K. (2008) A2B adenosine receptor signaling attenuates acute lung injury by enhancing alveolar fluid clearance in mice. Journal of Clinical Investigation, 118, 3301-3315.

[11] Eckle, T., Krahn, T., Grenz, A., Köhler, D., Mittelbronn, M., Ledent, C., et al. (2007) Cardioprotection by ecto-5'nucleotidase (CD73) and A2B adenosine receptors. Circulation, 115, 1581-1590.

[12] Eltzschig, H.K., Ibla, J.C., Furuta, G.T., Leonard, M.O., Jacobson, K.A., Enjyoji, K., et al. (2003) Coordinated adenine nucleotide phosphohydrolysis and nucleoside signaling in posthypoxic endothelium: Role of ectonucleotidases and adenosine $\mathrm{A} 2 \mathrm{~B}$ receptors. The Journal of Experimental Medicine, 198, 783-796. http://dx.doi.org/10.1084/jem.20030891

[13] Yang, D., Zhang, Y., Nguyen, H.G., Koupenova, M., Chauhan, A.K., Makitalo, M., et al. (2006) The A2B adenosine receptor protects against inflammation and excessive vascular adhesion. Journal of Clinical Investigation, 116, 1913-1923.

http://dx.doi.org/10.1172/JCI27933

[14] Hoffmann, D., Bijol, V., Krishnamoorthy, A., Gonzalez, V.R., Frendl, G., Zhang, Q., et al. (2012) Fibrinogen excretion in the urine and immunoreactivity in the kidney serves as a translational biomarker for acute kidney injury. American Journal of Pathology, 181, 818-828. http://dx.doi.org/10.1016/j.ajpath.2012.06.004

[15] McCoy, D.E., Bhattacharya, S., Olson, B.A., Levier, D.G., Arend, L.J. and Spielma, W.S. (1993) The renal adenosine system: Structure, function, and regulation. Seminars in Nephrology, 13, 31-40.

[16] Fredholm, B.B., IJzerman, A.P., Jacobson, K.A., Klotz, K.N. and Linden, J. (2001) International Union of Pharmacology. XXV. Nomenclature and classification of adenosine receptors. Pharmacological Reviews, 53, 527-552.

[17] Rudnick, M.R., Berns, J.S., Cohen, R.M. and Goldfarb, S.
(1996) Contrast media-associated nephrotoxicity. Current Opinion in Nephrology and Hypertension, 5, 127-133. http://dx.doi.org/10.1097/00041552-199603000-00005

[18] Morcos, S.K. (1998) Contrast media-induced nephrotoxicity-Questions and answers. British Journal of Radiology, 71, 357-365.

[19] Heyman, S.N., Rosen, S. and Brezis, M. (1994) Radiocontrast nephropathy: A paradigm for the synergism between toxic and hypoxic insults in the kidney. Experimental Nephrology, 2, 153-157.

[20] Weisberg, L.S., Kurnik, P.B. and Kurnik, B.R. (1994) Risk of radiocontrast nephropathy in patients with and without diabetes mellitus. Kidney International, 45, 259265. http://dx.doi.org/10.1038/ki.1994.32

[21] Cramer, B.C., Parfrey, P.S., Hutchinson, T.A., Baran, D., Melanson, D.M., Ethier, R.E., et al. (1985) Renal function following infusion of radiologic contrast material. A prospective controlled study. JAMA Internal Medicine, $145,87-89$.

http://dx.doi.org/10.1001/archinte.1985.00360010115018

[22] Parfrey, P.S., Griffiths, S.M., Barrett, B.J., Paul, M.D., Genge, M., Withers, J., et al. (1989) Contrast materialinduced renal failure in patients with diabetes mellitus, renal insufficiency, or both. A prospective controlled study. The New England Journal of Medicine, 320, 143-149.

[23] McDonald, J.S., McDonald, R.J., Comin, J., et al. (2013) Frequency of acute kidney injury following intravenous contrast medium administration: A systematic review and meta-analysis. Radiology, 267, 119-128. http://dx.doi.org/10.1148/radiol.12121460

[24] Wong, P.C., Li, Z., Guo, J. and Zhang, A. (2012) Pathophysiology of contrast-induced nephropathy. International Journal of Cardiology, 158, 186-192. http://dx.doi.org/10.1016/j.ijcard.2011.06.115 